\title{
Los conceptos de no-lugar y heterotopía en el análisis literario. Propuesta de relectura de Los autonautas de la cosmopista de Julio Cortázar
}

\author{
LIESBETH FRANÇOIS \\ Universidad de Lovaina
}

\begin{abstract}
Resumen
Muchas aproximaciones recientes a la literatura contemporánea se refieren a la teoría de los no-lugares del antropólogo francés Marc Augé, expuesta en su libro Non-lieux: Introduction à une anthropologie de la surmodernité (1992). Sin embargo, el concepto de 'no-lugar', por lo general, pierde parte de su potencial teórico al aplicarse de manera vaga y poco específica. Este artículo procura demostrar la productividad de un uso más consciente de la teoría de Augé y de la combinación del concepto de no-lugar con el de la heterotopía de Michel Foucault. Como piedra de toque propone analizar en Los autonautas de la cosmopista de Julio Cortázar (1983) la construcción de la imagen de la carretera como no-lugar heterotópico, así como en su progresiva desconstrucción. En su conjunto, el artículo ilustra la posibilidad de efectuar una lectura innovadora de los escritos del autor argentino mediante teorías actuales acerca del espacio y del lugar.
\end{abstract}

Palabras clave: no-lugar, Augé, heterotopía, Cortázar, autonautas

\begin{abstract}
Many approaches to contemporary literature currently employ French anthropologist Marc Augé's theory of nonplaces, as set out in his book Non-lieux: Introduction à une anthropologie de la surmodernité (1992). It is, however, important to note that the concept quite often loses an important part of its theoretical value when being applied in too broad a sense. In this article, we want to demonstrate the productivity of a more rigorous use of Augé's theory, and of its combination with Michel Foucault's concept of heterotopia. Our touchstone is Los autonautas de la cosmopista (1983), the last book of Julio Cortázar, in which we will analyze the construction of the image of the highway as a "heterotopic nonplace", as well as its gradual deconstruction. This way, we hope to illustrate the possibility of performing an innovative reading of Cortázar's writings by means of contemporary theories on space.
\end{abstract}

Keywords: nonplace, Augé, heterotopia, Cortázar, autonautes 


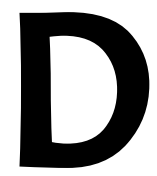
esde su aparición en 1992, el libro Non-lieux: Introduction à une anthropologie de la surmodernité del antropólogo francés Marc Augé contó con un gran interés crítico dentro del dominio de las ciencias humanas. El marco teórico de la sobremodernidad propuesto por Augé describe la época contemporánea como una era dominada por el exceso de información y de percepciones. Esta tendencia a la sobreabundancia, según el antropólogo, se hace visible en la proliferación de los llamados no-lugares: espacios de tránsito y de circulación rápida en que los puntos de referencia sociales están ausentes. De esta manera, la teoría del francés pudo introducirse con éxito en varios paradigmas que dan cuenta del impacto de algunos cambios drásticos en el mundo actual. Éstos, en efecto, precisamente estudian la influencia de la sociedad contemporánea -marcada entre otras cosas por fenómenos como la globalización, la migración y la fragmentación (Jameson y Miyoshi, 1998; Kaplan, 1996) - en la configuración social y antropológica de comunidades, así como en la percepción del tiempo y del espacio. No debe extrañar, por consiguiente, que esta teoría no haya tardado en aparecer también en los estudios del arte y de la literatura contemporáneos, sobre todo desde la década de 1990, con en el creciente por la representación de estos fenómenos en el arte.

Sin embargo, es de advertir que aunque muchos análisis incorporan el concepto de no-lugar y que, en la mayoría de los casos, también adoptan el marco de la sobremodernidad, hasta el día de hoy no se ha llevado a cabo una reflexión consistente acerca del papel que puede desempeñar la teoría de Augé en el estudio de las obras de arte, y específicamente en la investigación literaria. Es decir, en muchos casos su utilización no pasa de una breve alusión a Non-lieux en el contexto de un análisis textual específico - y esto sin ninguna profundización en el valor heurístico de la propuesta de Augé dentro del marco propiamente literario-, y varias veces la flexibilidad misma de la noción lleva a una confusión conceptual y a una neutralización de su carga teórica y semántica.

En reacción a esa falta de elaboración, creemos que es vital una colaboración interdisciplinaria fructífera entre los ámbitos de la antropología y de los estudios literarios, tomando en cuenta desde luego las exigencias y las especificidades de ambos campos. Por eso, uno de los objetivos del presente artículo consiste en estimular la reflexión acerca del uso de esta aproximación antropo- 
lógica en el dominio de la investigación literaria. Asimismo, la confusión que puede conllevar un término tan sugestivo como el de no-lugar, necesita de una precisión terminológica. Aunque reconocemos que puede ser productivo enfocar esta noción desde una perspectiva teórica diferente pero afín, muchas veces se malinterpreta como una mera ausencia de lugar o como lo opuesto de otro significado del término lugar.

El punto de arranque de este artículo es teórico, pero el centro de atención va desplazándose hacia la práctica concreta del análisis literario. En un primer movimiento, elaboramos un modelo de análisis textual que combina el concepto de no-lugar con el de heterotopía de Michel Foucault. Este primer paso va a la par con la reflexión teórica defendida aquí arriba acerca del uso de conceptos antropológicos y sociológicos en la investigación literaria, que servirá para modelar la práctica de análisis propuesta. La segunda parte de esta contribución se concentrará en el análisis concreto de Los autonautas de la cosmopista (1983) de Julio Cortázar y Carol Dunlop, que funcionará como piedra de toque para la factibilidad y la productividad de nuestro modelo. Veremos cómo los autores ponen en juego las teorías en cuestión a la vez que lanzan un desafío a ciertos estereotipos que éstas pueden producir. Conviene observar, sin embargo, que nuestra discusión sobre este libro no se limita a una mera ejemplificación del método por el que abogamos, sino que también aspira a efectuar una lectura innovadora del autor argentino. De esta manera, quiere ser una contribución y -ojalá- una fuente de inspiración para una revalorización de Cortázar dentro de nuestro paradigma contemporáneo, originada por Carlos J. Alonso en su libro Julio Cortázar: New Readings (1998).

\section{Marco teórico}

Augé en Non-lieux arranca de la voluntad de encontrar un nuevo término para designar nuestra época contemporánea, distinto del vago, negativo y muchas veces problemático concepto de posmodernidad. En efecto, en vez de representar el periodo en que vivimos como una superación o una pérdida de la modernidad, el antropólogo propone verlo como una intensificación de la misma y propone para ello la noción de sobremodernidad. Lo que rige nuestro mundo 
sobremoderno en esta óptica es un exceso tridimensional: de tiempo (sobreabundancia de eventos por, entre otras cosas, la difusión rápida de las noticias), de espacio (el desarrollo de los medios de transporte posibilita recorrer largas distancias en poco tiempo y las imágenes de otros lugares nos llegan de todas partes por los medios de comunicación) y de individualidad (cada uno quiere interpretar a su manera la información).

Con estas consideraciones como telón de fondo, Augé profundiza en el aspecto espacial de su propuesta y describe un nuevo tipo de sitio, cuya aparición y difusión se vinculan estrechamente con el fenómeno de la sobremodernidad, a saber, el no-lugar. Con este término, el francés agrupa los espacios que sirven para organizar la circulación rápida de personas y de bienes (aeropuertos, estaciones, etc.), los medios de transporte (trenes, aviones, etc.), los grandes centros comerciales y los campamentos de refugiados (Augé, 1992: 48). Lo que estos sitios tienen en común, al lado de su conexión con la idea de la sobremodernidad, es que se oponen diametralmente a lo que Augé define como el "lugar (antropológico)". En la terminología de Augé, el lugar es un sitio que se experimenta de una manera particular dentro de una comunidad: es identitario (constituye en parte la identidad del individuo que lo habita), relacional (define la relación del habitante a los otros individuos) e histórico (proporciona puntos de referencia que son el resultado de una evolución histórica). El no-lugar, entonces, corresponde a todo lo contrario: no es identitario, ya que no es capaz de definir o diferenciar identidades individuales (todos los que pasan por un no-lugar son viajeros, refugiados, etc.); no es relacional, sino que comporta una experiencia particular de soledad (se está solo entre muchos individuos que no están dispuestos a entablar contactos entre sí); y no es histórico por el hecho de que la actualidad y la velocidad reinan en estos espacios, borrando toda referencia histórica o - eventualmente- convirtiéndola en una curiosidad. Al final, reanudando con el punto de partida de sus consideraciones, Augé afirma que los no-lugares son los productos y las expresiones más completas de la sobremodernidad. En estos sitios, la vida es susceptible de experimentarse como fugaz, solitaria y anónima por el exceso tridimensional de la sociedad sobremoderna, con el que la mayoría de la gente todavía no se ha familiarizado. 
La falta de familiaridad de los no-lugares y del contexto sobremoderno en general revela un vínculo interesante entre esta teoría y la noción de heterotopía que avanza Foucault en su artículo "Des espaces autres", publicado en 1984. Cabe recordar que el filósofo francés define la heterotopía en términos de alteridad, aunque también sugiere cierto parecido con el resto del espacio: es un sitio absolutamente otro, que a la vez refleja los otros emplazamientos y los contesta torciendo su imagen. En este sentido, es una especie de utopía real, ya que la utopía siempre mantiene una relación de analogía directa o inversa con el espacio existente (Foucault, 2001: 15741575). En el resto de su texto, Foucault propone algunos principios para la heterotopología, a fin de describir el carácter particular de estos sitios. Con estas ideas en mente, no es difícil aprehender que las nociones de no-lugar y heterotopía se cubren parcialmente en su aplicación, ya que muchos no-lugares en efecto se vinculan estrechamente con el espacio que los rodea - espacio ocupado por emplazamientos que corresponden al resto del continuo entre lugar y no-lugar- al mismo tiempo que difieren radicalmente del mundo circundante por la culminación del exceso sobremoderno en ellos.

Como se verá a continuación, podemos representar el vínculo entre los dos conceptos recurriendo a un modelo de solapamiento parcial. Su uso combinado además se revela productivo en el análisis de la construcción del espacio en el texto literario, ya que permite salir en parte de la dicotomía lugar/no-lugar por la presencia de una tercera noción, y describir de manera flexible las relaciones entre el no-lugar heterotópico y el resto del espacio (por el doble valor de reflexión y de contestación de la heterotopía). Otra ventaja de la combinación se relaciona con el hecho de que la heterotopicidad es un parámetro importante en la descripción de los valores simbólicos y sociales vinculados a la representación del espacio en el texto; proporciona información significativa acerca de la "normalidad" de ciertas experiencias del espacio y posibilita captar en plenitud la carga simbólica del no-lugar.

Ahora bien, creemos que la descripción de la relación entre los dos conceptos se efectúa de manera más eficaz y flexible si se apoya en una organización prototípica de sus instancias y de la manera en que se solapan. Fue la psicóloga Eleanor Rosch la que avanzó la teoría de la prototipicidad en los años setenta 
como alternativa a la concepción clásica de clasificación, según la cual la pertenencia de un elemento a una categoría depende del cumplimiento de toda una serie de condiciones necesarias y suficientes. En oposición a esta perspectiva tradicional, el enfoque de Rosch propone tener en cuenta las relaciones entre los diversos elementos y la "tipicidad" de cada caso, con vistas a constituir categorías graduadas, flexibles, y de límites borrosos, que se organizan alrededor de un núcleo prototípico (Rosch y Mervis, 1975; Geeraerts, 2006). En nuestra opinión, este modo de organización es óptimo, ya que posibilita una categorización flexible pero aprehensible de los casos concretos del (no-lugar o de la heterotopía). En lo que sigue, proponemos una representación esquemática de la manera en que las nociones de Augé y de Foucault se solapan, que estructuramos con ayuda de los ejemplos más típicos de cada caso. Así, gracias a teoría de la prototipicidad nos adentramos en la interacción entre el análisis práctico y el plano teórico.

La Figura 1, representa de manera simplificada este modelo de solapamiento derivado de la comparación entre diferentes tipos de no-lugares y de heterotopías. En la zona central, que cubre los casos que son representativos tantos del no-lugar como de la heterotopía, se encuentran el motel y el campamento de refugiados. Estos sitios - ambos utilizados a manera de ejemplificación por Augé (1992: 48) o por Foucault (2001: 1576) — son radicalmente "otros" en su reflejo distorsionado de las estructuras y de las apariencias del mundo circundante, y presentan claramente las características identitarias, relacionales e históricas negativas del no-lugar. Igualmente hay una zona de solapamiento entre lugar y heterotopía, e incluso existe un conjunto de heterotopías que no cabe en la teoría que opone el lugar al no-lugar. En efecto, no todas las heterotopías son no-lugares; algunas corresponden mejor a la definición del lugar antropológico de Augé (como la iglesia, el monumento, el jardín, etc.) y otros caen fuera de la dicotomía lugar/no-lugar porque se trata de espacios apenas afectados por la presencia humana (como el bosque, el desierto o la selva). Al revés, finalmente, no todos los no-lugares son heterotopías, ya que la heterotopicidad de los sitios depende de su grado de integración en el espacio "normal" de cada día. Así, los no-lugares de la calle y del supermercado apenas son susceptibles de ser 
Figura 1

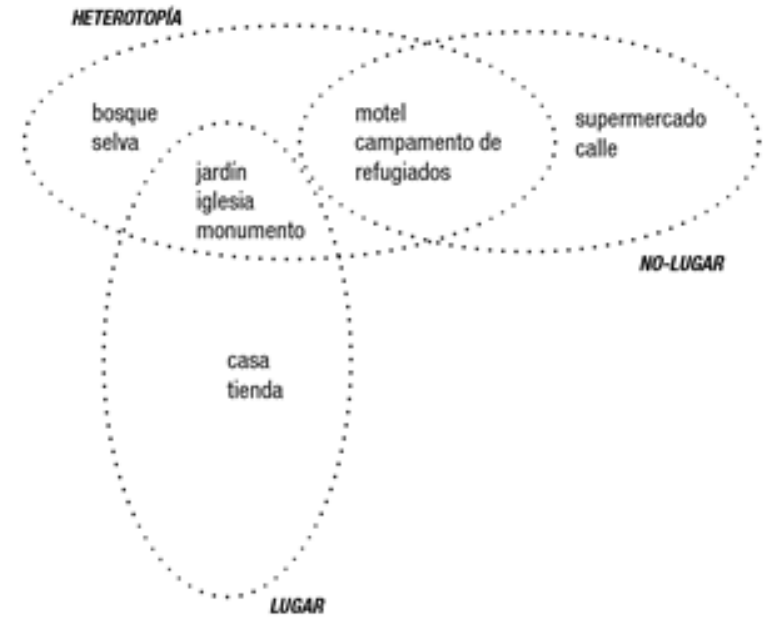

descritos con el término de heterotopía, por ser sitios centrales y normalizados en nuestra práctica del espacio diario. ${ }^{1}$

Desde luego, esta primera propuesta corresponde a una representación muy esquemática y sólo parcialmente generalizable de las relaciones entre el (no-)lugar y la heterotopía. ${ }^{2}$ Por eso, conviene detenerse en la manera en que se utiliza en la práctica del análisis textual. En primer lugar, importa aplicar el esquema expuesto de acuerdo a su naturaleza prototípica y su flexibilidad (véase la Figura 2, que sugiere una transición gradual entre las categorías). Así, en vez de aplicarlo como una categorización fija y preestablecida, hay que determinar para cada caso en qué medida un ejemplo concreto de uno de los conceptos

1 Para una discusión del carácter heterotópico o no de estos espacios, véase el tercer capítulo de Heterotopia and the City (Dehaene, 2008).

2 Queda claro que tanto las teorías de Augé y de Foucault como nuestra propuesta de combinarlas presentan limitaciones; parten de una perspectiva preponderantemente "occidental" y sobre todo se trata de una voz "exterior" a los no-lugares, que pertenece a los que están acostumbrados a vivir en el lugar antropológico de Augé. Sin embargo, esperamos que con los matices que siguen podemos remediar en parte estos defectos. 
Figura 2

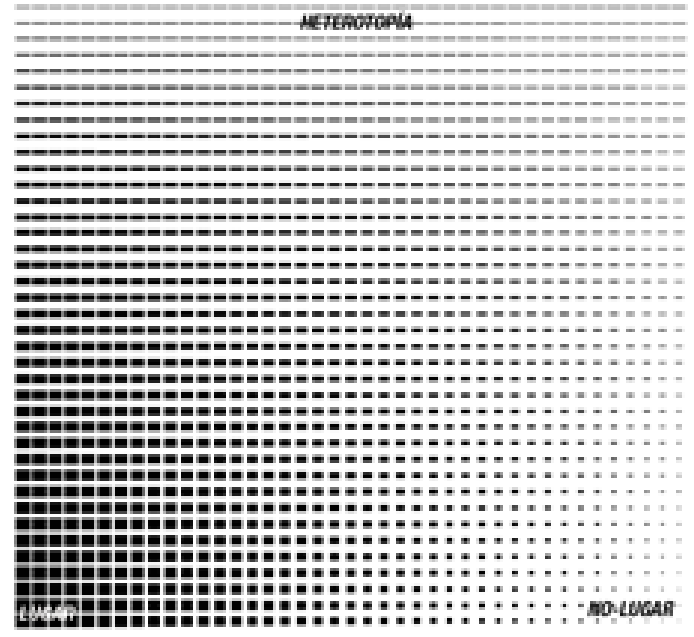

en cuestión cumple los rasgos prototípicos del (no-)lugar o de la heterotopía. ${ }^{3}$ Asimismo, la conexión entre las características típicas del (no-)lugar y de la heterotopía debe verificarse también respecto al caso concreto que se estudia. De esta manera, igualmente será posible incorporar ejemplos menos típicos y estudiar los casos en que no se dan las relaciones presupuestas entre los conceptos.

En segundo lugar, queda claro que el paso de la teoría a la práctica es mediado por los factores de la percepción individual, del imaginario social y de la construcción de imágenes literaria. Por la naturaleza misma de los conceptos de Augé y de Foucault —ambos se refieren a espacios materialmente existentes a la vez que a la percepción compartida de estos espacios (Cfr. Augé, 1992: 73; y Foucault, 2001: 1575) - se debe prever la acción de la subjetividad y de los mecanismos de percepción sociales en las imágenes de estos sitios. Es evidente que, sobre todo en el caso de la literatura, la relación entre el estatuto ontológico del espacio y sus diferentes representaciones sociales e individuales desempeña un papel predominante en el análisis.

3 Características identitarias, relacionales e históricas; descripciones compatibles con los seis principios de la heterotopología según Foucault; y presencia de una relación con el contexto de la sobremodernidad. 


\section{El no-lugar heterotópico en Los autonautas de la cosmopista de Julio Cortázar}

Este modelo teórico es sumamente útil a la hora de analizar la representación del espacio en textos como Los autonautas de la cosmopista, en que la experiencia espacial sobremoderna desempeña un papel clave. Además, ofrece posibilidades productivas para el estudio de la literatura desde una perspectiva crítica innovadora y profundamente actual, y esto es precisamente lo que está en juego en el caso de Julio Cortázar. En efecto, a partir de los últimos años de la década de 1990 se ha explorado la posibilidad de sobrepasar la visión estereotipada del autor argentino como modernista y de introducirlo en un campo de estudio más actual.

La iniciativa para tal revalorización de Cortázar fue lanzada por Carlos J. Alonso, quien, en busca de "las respuestas a la pregunta de cómo la relevancia de Cortázar puede ser renegociada desde nuestro presente crítico" (1998: 3, trad. nuestra), editó el volumen Julio Cortázar: New Readings (1998). Los ensayos que aparecen en esta colección aspiran a echar una nueva mirada sobre los escritos del argentino en el marco de los estudios literarios contemporáneos. Globalmente, se pueden distinguir dos estrategias básicas utilizadas para tal fin por los autores de estos textos: la discusión de algunas cuestiones políticas en la obra de Cortázar que siguen siendo actuales (p. ej. el problema de la identidad argentina y latinoamericana) o el descubrimiento en sus textos de ideas y esquemas intelectuales postestructuralistas (p. ej. la socavación de las dicotomías). Recurriendo al modelo teórico propuesto en el apartado anterior, que remite a la experiencia diaria y compartida del mundo contemporáneo posnacional y globalizado, y a la prominencia actual del paradigma espacial dentro del estudio de las ciencias humanas, este artículo aspira a añadir otra perspectiva a estas dos tendencias predominantes.

Los autonautas de la cosmopista (1983), que resultó de la colaboración literaria entre Julio Cortázar y su esposa Carol Dunlop, fue una de sus últimas publicaciones. En este libro (semi)autobiográfico, los autores deciden dejar atrás la vida apresurada que tienen en París para vivir un mes de tranquilidad y de anonimato en los paraderos de la autopista del Sur, que va de París a Marsella. 
Conciben este viaje como una verdadera expedición y se proponen escribir un libro sobre sus experiencias en la carretera. Durante su exploración, la autopista y los paraderos van convirtiéndose por la imaginación y la creatividad de la pareja en un país utópico, en un reino de amor, de quietud y de sueños. Con sus reflexiones, los escritores quieren contrarrestar la imagen tradicional de la carretera como un espacio de apresuramiento, de ruido y de fealdad en favor de una idea más positiva impulsada por la observación minuciosa y la fantasía.

No es difícil comprender, por consiguiente, que se trata de un libro sumamente apto para aplicarle un análisis basado en las teorías de Augé y de Foucault, ya que su protagonista, la autopista, no sólo es uno de los no-lugares más prototípicos, sino que también está dotado de mucho potencial heterotópico. Como veremos a continuación, las experiencias típicas del no-lugar en el plano de la identidad, de la relacionalidad y de la historia, al igual que sus representaciones literarias, no sólo se reconocen fácilmente en las reflexiones de los autores, sino que también se transforman de manera creativa en su imaginación. Los escritores recurren al estereotipo de la sobreabundancia y de la velocidad para luego contrarrestarlo y desplazarlo hacia una visión más original sobre el no-lugar heterotópico. De esta manera, Cortázar y Dunlop incluso proporcionan un antídoto contra el exceso sobremoderno y sus efectos mayoritariamente negativos.

Aunque el libro parezca expresar sobre todo las experiencias y las ideas de sus autores, también se caracteriza por una pluralidad de voces. En efecto, Cortázar y Dunlop igualmente incluyen la opinión pública sobre la carretera en su crónica - la doxa, ${ }^{4}$ o la opinión de los viajeros "no iluminados", que todavía no han aprendido a mirar bien el espacio que atraviesan- y se distancian claramente de ella a fin de subrayar el mérito de su expedición. ${ }^{5} \mathrm{El}$ resultado es un texto estratificado que toma en cuenta la perspectiva de los otros conductores, reconstruida a partir de la observación de su comportamiento y de sus opiniones. Esta visión se representa por boca de algunos personajes ficticios (entre

4 Acerca del concepto de la doxa y su función, véase el artículo de Ruth Amossy (2002).

5 Aquí, se trata de una parodia de los discursos de los antiguos exploradores (Arias, 1996), conforme a la concepción lúdica de la realidad a la que adhieren los autores (Blanco, 1996). 
otros, una madre que escribe cartas a su hijo), o a través de la descripción de discusiones y observaciones reales. Cabe decir, sin embargo, que también pueden incluirse en este estrato las concepciones espontáneas de los dos autores antes de que emprendieran la expedición. Esta distinción entre la opinión pública espontánea y la perspectiva "científica" de los expedicionarios resulta sumamente útil para sacar a la luz el juego creativo con el fenómeno del no-lugar heterotópico.

En Los autonautas de la cosmopista los representantes de la opinión pública nos entregan la imagen más típica del no-lugar. Así, es posible reconocer las características prototípicas del no-lugar en el comportamiento de los otros viajeros y en el discurso de los representantes ficticios de la doxa: al nivel de la identidad, se hace hincapié en el anonimato y en la falta de diferencia entre los viajeros; las relaciones se reducen a un mínimo tanto en la carretera como en los paraderos - a los autores incluso no les da la gana entablar relaciones con la gente que entra y sale a toda prisa en el paradero-: "Pero casi todos entran en el parking con el aire de los que tienen la vejiga llena o el estómago vacío, y eso no reemplaza la inteligencia ni la sensibilidad" (133-134); y en el plano temporal, la velocidad reina y el momento presente eclipsa toda referencia histórica. La exageración y el efecto alienante de estas características convierten la autopista en una heterotopía, ya que representa el exceso de la sociedad sobremoderna, al mismo tiempo que lo impugna por las experiencias negativas que conlleva. La remitente de las cartas ficticias incluidas en el libro, por ejemplo, se siente muy incómoda cuando tiene que enfrentarse a los fenómenos sobremodernos que se dan en la autopista: "Imagínate que hubiéramos podido quedarnos sin gasolina en medio de toda esa gente que pasa a cientos de kilómetros por hora sin siquiera mirarte" (76).

En cambio, las reflexiones seudocientíficas y literarias de Cortázar y Dunlop logran desplazar esta imagen, compensando los efectos negativos del no-lugar o dirigiéndolos hacia experiencias positivas. La construcción de las referencias identitarias a las que se refiere Augé es el primer plano en el que opera su creatividad. Para comenzar, les llaman la atención las personas que sí se definen individualmente en relación con la autopista (obreros, tenderos, etc.) y los vínculos que mantienen entre sí: "Basta instalarse para descubrir que no sólo los 
viajeros lo ocupan durante la breve pausa de un pic-nic o del W.C.; una población más estable se mueve en su territorio, entregada a tareas de remodelamiento y de ampliación" (95). En esta cita, el lugar antropológico incluso no está lejos, pues la caracterización del conjunto de los obreros como una "población" supone una cierta estabilidad.

Al lado de esto, los autores notan que el no-lugar les ofrece la oportunidad de conocerse mejor a sí mismos ya que los libera de las circunstancias determinantes del lugar. En este sentido, nos muestran que quizás sea absurdo querer definirse con respecto a un lugar fijo y concreto en esta época de movilidad y de transnacionalidad - Cortázar y Dunlop de hecho son inmigrantes en Francia-. Así, relativizan la idea de una identidad preestablecida y estrechamente vinculada con el lugar de origen, y en algunos fragmentos incluso revisan la idea misma de una identidad individual incorporándose al flujo indiferenciado de los viajeros: "No, eso es al mismo tiempo autopista, asfalto y coches, un solo ser que respira y avanza [...]" (127) y "La autopista soy yo, tú, nosotros [...]" (297). ${ }^{6}$

La falta de relaciones se compensa con la apreciación de la relativa quietud provocada justamente por el anonimato de la autopista, y con la imaginación: “[...] además el dragón [es decir, el camping-car con el que viajan Cortázar y Dunlop] tiene su pinta e inspira respeto a los más pequeños y a veces a los grandes [...]" (237). En cambio, los autores al mismo tiempo dejan en claro que no es necesario considerar la carretera como un espacio de aislamiento y de soledad, ya que entablan relaciones con varios otros viajeros. Además, algunos amigos vienen a visitarlos precisamente por el carácter especial del sitio del encuentro. Éste es el caso, entre otros, de René, un viejo amigo de Cortázar:

René y yo no nos habíamos visto desde hacía por lo menos seis años, [...]. Podríamos habernos encontrado cien veces en París, pero los cronopios son así y de golpe a René se le antojó meterse en todos los paraderos uno tras otro hasta dar con nosotros [...]. ¿Lo movía el prestigio misterioso pero

6 Para el tema de la evaporación gradual de las fronteras entre el individuo y el mundo en Los autonautas de la cosmopista, véase el artículo de Jacques Leenhardt (1986). 
perceptible de la expedición? ¿O la nostalgia de una amistad que los dos descuidamos tanto en condiciones normales y pedestres? (87-89).

La experiencia temporal típica, por su parte, se ve contrarrestada por la índole de la expedición misma: los autores viajan a un ritmo de dos paraderos al día, por lo que la velocidad automáticamente se disminuye a un mínimo y se reemplaza por una sensación de tranquilidad e incluso de vacaciones: "No: justamente la autopista es lo que falta, para nosotros no es más que un rumor a la distancia que la costumbre reduce de día en día, que hemos asimilado sin esfuerzo al agradable resonar del mar Caribe en Martinica o Guadalupe" (132). Sin embargo, no sólo asistimos a una anulación de la prisa, sino también a concepciones alternativas del tiempo impulsadas por la estancia en la autopista, como el sentimiento de que se encuentran "fuera" del tiempo - el subtítulo del libro es "Un viaje atemporal París -- Marsella" - y la representación de la línea temporal como espiral: "La autopista no es una línea recta sino una espiral, nuestras dos vidas también espirales, y el vértigo de esas líneas que se cruzan, en el mosaico de los círculos y tangentes, paralelas e intersecciones [...]" (265).

El aporte de los autores en todos estos planos hace de la carretera un espacio otramente heterotópico: la heterotopía mantiene su valor de representación a la vez que de contestación, pero esta vez ya no se trata de ese espacio alienante que preferentemente se evita, sino de una heterotopía del sueño, del juego y de la imaginación. ${ }^{7}$ Dicho de otra manera, Cortázar y Dunlop crean una heterotopía en que los efectos de la sobremodernidad son atacados y compensados por la creatividad con la que se transforman sus características típicas: “¿No estamos dando a esta Francia de hoy un buen ejemplo de que la imaginación puede realmente tomar el poder si se olvida de las rutinas?" (320). En un movimiento paralelo, también hay pasajes en el libro que desplazan la imagen del no-lugar heterotópico hacia un lugar antropológico, ya que los autores varias veces logran encontrar referencias identitarias, relacionales e históricas en el espacio de la autopista. Es legítimo preguntarse si en este último caso todavía se

7 Para una discusión detallada de la correspondencia entre la imagen de la autopista y los seis principios de la heterotopología de Foucault, véase François, 2010. 
trata de una heterotopía; una respuesta positiva necesitaría una reflexión más amplia sobre el carácter posiblemente cada vez más heterotópico y excepcional del lugar en el mundo contemporáneo.

En último lugar, vale la pena describir la manera en que los rasgos que Marc Augé atribuye a nuestra época en general pueden reconocerse en Los autonautas de la cosmopista. La sobremodernidad, en efecto, no sólo está presente en el plano espacial, bajo la forma del no-lugar, sino que también se ve representada en la descripción de los excesos espantosos de espacio y de tiempo en el texto: “[...] apreciábamos la autopista a la vez que le reprochábamos un poco que fuera ese mal necesario del que tanto nosotros como los demás no podemos escapar en este siglo de velocidad obligatoria [...]" (28). Sin embargo, cabe decir que dichas sobreabundancias de nuevo se compensan con el proyecto de los autores: reducen la velocidad y toman su tiempo para explorar el espacio desconocido y desatendido por la mayoría de la gente que pasa por ella: "[...] era la prueba de que jamás habíamos mirado verdaderamente la autopista, puesto que hasta entonces creíamos que entre París y Marsella había una treintena de parkings" (37). En cambio, el exceso de individualidad no se censura en este libro; es más, los expedicionarios precisamente advierten el peligro de la adhesión ciega a la "doxa" y de la falta de reflexión individual. Su crítica irrumpe bajo forma de varios gestos de desautomatización de las percepciones estandarizadas, cuando se distancian lúdicamente de la gente que sigue aferrada a las apariencias superficiales: “Todo se coaguló en un segundo, y supimos la verdad: estábamos en el lugar donde se castiga y se ajusticia a las brujas, y el paradero era una obra maestra de camuflaje destinada a ocultar lo que sólo una expedición y una veteranía como la nuestra podían descubrir" (335). Sin embargo, la sobreabundancia de perspectivas sí se trasluce en el discurso paródico de los autores. Los términos seudoespecializados que utilizan los expedicionarios al igual que la mimesis burlesca de discursos científicos remiten a la fragmentación del saber tan típica de nuestra época sobremoderna ( Cfr. Cipolloni, 2002: 367-368). 


\section{Conclusiones}

En conclusión, la presencia de fenómenos y experiencias típicos de la sobremodernidad, al igual que su gradual transformación en el discurso literario, son manifiestas en Los autonautas de la cosmopista. El primer apartado de este artículo reveló los vínculos entre los conceptos de no-lugar de Augé y de heterotopía de Foucault, y elaboró un modelo para su aplicación combinada al análisis del texto. Al mismo tiempo, se insistió en la carga semántica y teórica de las nociones, al igual que en su flexibilidad. En el segundo apartado, se explicó que es posible estudiar este libro de Cortázar desde la crítica literaria contemporánea recurriendo precisamente a este modelo, que por la perspectiva de Augé se centra en el carácter particular de la época presente. En efecto, el análisis de la descripción de la autopista hizo ver que el no-lugar está presente en este texto con todas sus características identitarias, relacionales e históricas, pero que al mismo tiempo sufre una transformación creativa en el relato del viaje, que desplaza la visión heterotópica tradicional a otra heterotopía mucho más positiva. En su renegociación de las características típicas del no-lugar sobremoderno de la carretera y de la heterotopicidad de este sitio, Los autonautas de la cosmopista cobra relevancia en el paisaje académico contemporáneo. Siguiendo la misma línea de pensamiento, podemos sugerir que merece la pena estudiar desde esta perspectiva varios otros textos de Julio Cortázar en que los no-lugares desempeñan un papel clave (piénsese sólo en cuentos como "La autopista del Sur", "Manuscrito hallado en un bolsillo", 8 "La noche boca arriba", etc.; o en el simbolismo del espacio en Rayuela). Creemos que es una línea de investigación interesante, que abre posibilidades para nuevas lecturas de la obra de Cortázar. Ojalá nuestro artículo, además de ofrecer un ejemplo más de una lectura contemporánea del escritor argentino, sea también una fuente de inspiración para el análisis espacial de muchas obras literarias que se vinculan con la actualidad.

8 Este cuento fue estudiado desde la óptica del no-lugar por Ana Lozano de la Pola (2006). 


\section{Referencias bibliográficas}

ALONSO, Carlos J. (ed.) (1998): Julio Cortázar: New Readings. Cambridge: Cambridge University Press.

AMOSSY, Ruth (2002): "Introduction to the study of doxa". En Poetics Today. Núm. 23: 3, pp. 369-394.

ARIAS CAREAGA, Raquel (1996): "Julio Cortázar y un libro de viajes del siglo XX”. En Manuel Criado de Val (ed.), Caminería literaria e hispanoamericana. Caminería hispánica: actas del II Congreso Internacional de Caminería Hispánica. Vol. III. Guadalajara: Aache, pp. 811-822.

AUGÉ, Marc (1992): Non-lieux. Introduction à une anthropologie de la surmodernité. París: Seuil.

BLANCO ARNEJO, María Dolores (1996): La novela lúdica experimental de Julio Cortázar. Madrid: Pliegos.

CIPOLLONI, Marco (2002): "Pseudospecialismo, non luogo e parodia: fenomenologia paraletteraria dello sradicamento da Larra a Cortázar". En Domenico Antonio Cusato y Loretta Frattale (eds.), La penna di venere. Scritture dell'amore nelle culture iberiche. Atti del XX Convegno dell'Associazione degli Ispanisti Italiani (Firenze 15-17 marzo 2001). Messina: Andrea Lippolis, pp. 367-376.

CORTÁZAR, Julio (1974): “Manuscrito hallado en un bolsillo". En Octaedro. Madrid: Alianza, pp. 49-65.

CORTÁZAR, Julio (1981): "La noche boca arriba". En El perseguidor y otros relatos (comp. Alberto Cousté). Barcelona: Bruguera, pp. 42-50.

CORTÁZAR, Julio (1991): "La autopista del Sur". En La autopista del sur y otras historias (ed. Luis G. Martín). Madrid: Bruño, pp. 103-135.

CORTÁZAR, Julio (2007): Rayuela (ed. Andrés Amorós). Madrid: Cátedra.

CORTÁZAR, Julio y Carol Dunlop (2007): Los autonautas de la cosmopista o un viaje atemporal París -- Marsella. Buenos Aires: Alfaguara. 
DEHAENE, Michiel y Lieven De Cauter (eds.) (2008): Heterotopia and the City. Public Space in a Postcivil Society. Londres/Nueva York: Routledge.

FOUCAULT, Michel (2001): “Des espaces autres”. En Daniel Defert y François Ewald (eds.), Dits et écrits 1954-1988. París: Gallimard, pp. 1571-1581.

FRANÇOIS, Liesbeth (2010): Los autonautas de la cosmopista (1983) de Julio Cortázar. Un enfoque espacial. Tesina de Licenciatura. Lovaina: Universidad de Lovaina.

GEERAERTS, Dirk (2006): “Prospects and problems of prototype theory”. En Geeraerts, D. (ed.), Cognitive Linguistics: Basic Readings. Berlín/Nueva York: Mouton de Gruyter, pp. 141-166.

HARVEY, David (1990): The Condition of Postmodernity. An Enquiry into Origins of Cultural Change. Malden, Oxford, Carlton: Blackwell.

HENNUY, Jean-Frédéric (2006): “Examen d'identité: voyageur professionnel et identification diasporique chez Jean-Philippe Toussaint et Abdelk Bir Khatibi”. En French Studies. Núm 60: 3, pp. 347-363.

JAMESON, Fredric y Masao Miyoshi (eds.) (1998): The Cultures of Globalization. Durham: Duke University Press.

KAPLAN, Caren (1996): Questions of Travel. Postmodern Discourses of Displacement. Durham: Duke University Press.

LEENHARDT, Jacques (1986): "Un chemin de la connaisance: 'Les autonautes de la cosmoroute". En Centre de recherches Latino-Américaines de l'Université de Poitiers, Coloquio Internacional: Lo lúdico y lo fantástico en la obra de Cortázar. Vol. I. Madrid: Fundamentos, pp. 77-84.

LIPOVETSKY, Gilles y Sébastien Charles (2006): Les Temps hypermodernes. París: Livre de Poche.

LOZANO DE LA POLA, Ana (2006): "Líneas del bajo nivel. Cuando Cortázar viaja en métro". En Extravío. Revista electrónica de literatura comparada. Núm. 1. Disponible en http://www.uv.es/extravio/PDFs/A_LOZANO.PDF. [Consulta: 6 de diciembre de 2010]. 
MATTILLE, Laurent (2009): "L'horizon urbain dans la littérature de la surmodernité. Retrouver le paysage”. En Articulo. Núm. Hors-série 2. Disponible en https://articulo.revues.org/1118. [Consulta: 6 de diciembre de 2010].

NEYRET, Juan Pablo (2007): "Postal de La Habana: lugares y no lugares en Adiós mariquita linda de Pedro Lemebel”. En Espéculo. Revista de Estudios Literarios. Núm. 34. Disponible en https://pendientedemigracion.ucm.es/info/especulo/numero34/lemebel.html. [Consulta: $6 \mathrm{de}$ diciembre de 2010].

O'BEIRNE, Emer (2006): "Navigating non-lieux in contemporary fiction: Houellebecq, Darrieussecq, Echenoz, Augé”. En The Modern Language Review. Núm. 101: 2, pp. 388-401.

PÈRCOPO, Luisa (2008): "Lieux et non-lieux: subverting spaces of recognition and belonging in Looking for Alibrandi”. En Studies in Australasian Cinema. Núm. 2: 1, pp. 21-31.

ROBERTS, Les (2002): “'Welcome to Dreamland': From Place to Non-place and Back Again in Pawel Pawlikowski's Last Resort". En New Cinemas: Journal of Contemporary Film. Núm. 1: 2, pp. 78-90.

ROSCH, Eleanor y Carolyn B. Mervis (1975): "Family Resemblances: Studies in the Internal Structure of Categories". En Cognitive Psychology. Núm. 7, pp. 573-605.

STRONACH, Ian (1996): "Fashioning Post-modernism, Finishing Modernism. Tales from the Fitting Room". En British Educational Research Journal. Núm. 22: 3, pp. 359-375.

VIZCAÍNO MACERO, Candelaria (2005): "Los espacios simbólicos en El Rey Lear de W. Shakespeare a través de la adaptación fílmica de A. Kurosawa en Ran”. En Cauce. Revista Internacional de Filología y su Didáctica. Núm. 28, pp. 439-468. 